\title{
AVALIAÇÃO DE SISTEMAS ALIMENTARES PARA TERNEIROS DESMAMADOS AOS TRÊS MESES DE IDADE
}

\author{
EVALUATION OF FEEDING SYSTEMS FOR CALVES WEANED \\ AT THREE MONTHS OLD
}

\section{Roblein Cristal Coelho Filho ${ }^{1}$ Fernando Luiz Ferreira de Quadros ${ }^{2}$ Glênio Lopes dos Santos ${ }^{3}$}

\section{RESUMO}

Objetivando avaliar o desempenho de terneiros desmamados aos 3 meses de idade em quatro diferentes sistemas alimentares: $S_{I}$ - Campo Nativo + Silagem de Sorgo (Sorghum bicolor); $S_{2}$ - Campo Nativo + Pastagem cultivada de inverno (Avena strigosa + Lolium multiflorum); $S_{3}$-Pensacola (Paspalum notatum var. Saurae) + silagem de sorgo; e $S_{4}-$ Pensacola + pastagem cultivada de inverno, bem como a qualidade destes sistemas expresso em proteina bruta e digestibilidade in vitro da matéria orgânica, foi realizado um experimento nas dependências da Pulquéria Agropecuária, em São Sepé, Depressão Central do $R S$, em solo da unidade de mapeamento Cerrito, classificado como Laterítico Bruno Avermelhado distrófico. $O$ delineamento experimental foi o inteiramente casualisado, tendo os animais como repetições. Utilizaram-se 30 terneiros cruza Nelore $x$ Charolês, em pastejo contínuo com lotação variável. O periodo experimental foi de 244 dias (verão/outono e inverno/primavera). Os animais foram pesados com intervalos médios de 28 dias. O sistema $S_{\downarrow}$, apresentou um Ganho Médio Diário de peso (545g) superior aos demais $(P<0,05)$, não diferindo significativamente do sistema $S_{2}(475 \mathrm{~g})$, no total do periodo experimental. Quando analisados os periodos em separados, verifica-se que no verão/outono, não houve diferença significativa entre campo nativo e pensacola, porém no inverno/primavera verifica-se que os animais submetidos à pastagem cultivada apresentaram desempenho superior aqueles submetidos à silagem de sorgo acrescida de um suplemento.
Palavras-chave: desmame precoce, forrageiras, pastagem nativa, pensacola, aveia preta, azevém, silagem de sorgo.

\section{SUMMARY}

A trial was conducted to evaluate the performance of calves weaned of three months old in four systems: $S_{1}-$ Natural pasture + Sorghum bicolor silage; $S_{2}$-Natural pasture + Winter pasture (Avena strigosa + Lolium multiflorum); $S_{3}-$ Bahiagrass (Paspalum notatum var. Saurae) + Sorghum silage and $S_{+}$Bahiagrass + Winter pasture. The experiment was installed in Pulquéria Agropecuária, São Sepé, RS, in a Ridish-Brown Latheritic Soil. It was evaluated the crude protein and in vitro organic matter digestibility of the forage. Thirty calves, Nelore $x$ Charolais Breed, were used as replications, in a completely randomized design, with continuous grazing and variable stocking rate in the pastures. The experimental period was of 244 days (summer/autumn and winter/spring). The calves were weighted at a 28 day intervals. $S_{4}$ system presented a daily liveweight gain $(545 \mathrm{~g})$ higher than the others $(P<0.05)$, except for the $S_{2}$ system $(475 \mathrm{~g})$, in the total experimental period.

Key words: calves, weaning, feeding systems, forrages, natural pasture, Bahiagrass, oats ryegrass, sorghum silage.

\footnotetext{
${ }^{\text {l}}$ Engenheiro Agrônomo, Bolsista de Aperfeiçoamento FAPERGS, Departamento de Zootecnia, Universidade Federal de Santa Maria (UFSM).

${ }^{2}$ Engenheiro Agrônomo, MSc., Professor Assistente, Departamento de Zootecnia, Centro de Ciências Rurais, UFSM, 97119-900, Santa Maria-RS. Autor para correspondência.

${ }^{3}$ Engenheiro Agrônomo, PhD., Professor Titular, Departamento de Zootecnia, UFSM. Recebido para publicação em 05.09.94. Aprovado em 13.09.95
} 


\section{INTRODUÇÃO}

A exploração de bovinos para corte criados em condição de campo nativo no Rio Grande do Sul, apresenta índices de produtividade extremamente baixos, como desfrute inferior a $11 \%$, natalidade de $50 \%$ e lotação bem inferior a uma cabeça/ha (IBGE,1985). Esta situação acarreta uma grande ociosidade nos campos, levando-se em conta que, anualmente, cerca de 1.600 .000 ha são ocupados por vacas que não produzem. GRAWUNDER \& MIELITZ NETO (1989) indicam o aumento da taxa de natalidade e não a redução da idade de abate, como uma das formas mais econômicas e práticas para melhorar o desempenho da produção pecuária do Estado. Agrega-se a isto o fato de que as exigências nutricionais na lactação são bem maiores que no período de gestação. A elevação da taxa de natalidade, associada a práticas de manejo viáveis como o desmame aos 90 dias, torna-se muito significativa economicamente se comparada a redução da idade de abate, pois esta última requer maiores investimentos com a implantação e manutenção de pastagens cultivadas. O desmame antecipado, deve ser considerado um instrumento de manejo que pode ser utilizado para aumentar a produtividade do gado de corte, onde a fertilidade é baixa. Considerando razoável o aumento do índice de nascimento de 50 para $75 \%$, através do desmame antecipado, aos 3 meses de idade, o qual é um sistema mais fácil e econômico de aumentar a fertilidade, do que aumentar as condições alimentares para a vaca, sendo que esta prática proporciona índices de fecundação semelhantes aqueles obtidos com a utilização de pastagens cultivadas.

Portanto, surge daí a necessidade de desmamar os terneiros o mais cedo possível, a fim de proporcionar às vacas condições de entrarem novamente em cio e de se recuperarem antes da entrada do inverno. Segundo observações feitas pela EMATER-RS a níveis de propriedades rurais, o percentual de prenhez em vacas submetidas ao desmame aos 90 dias foi superior a $75 \% \mathrm{em}$ observações realizadas nos anos de 1982 a 1986 (GRAWUNDER et al., 1986).

A mensuração do desempenho de terneiros desmamados precocemente, quando submetidos a diferentes pastagens cultivadas e naturais, em diferentes estações do ano, poderá trazer muitas informações sobre as formas mais econômicas e práticas de condução dos terneiros após o desmame, sendo estas informações do maior interesse para a pesquisa, serviço de extensão rural e principalmente para os produtores rurais.
Em Tupanciretã, RS, LEAL et al. (1978), comparando o desenvolvimento de terneiras da raça Charolês, desmamadas aos 110 e 205 dias de idade, bem como o desempenho reprodutivo das respectivas mães, constatou que: $O$ desempenho das terneiras desmamadas naquelas idades foi semelhante, e que as vacas que desaleitaram aos 110 dias de idade apresentaram maior índice de cio. CRISTALDO \& LOBATO (1990), em Eldorado do Sul, RS, comparando 2 idades de desmame de terneiras $(100 \mathrm{e}$ 150 dias de idade), com o objetivo de obter peso adequado ao acasalamento aos 24-27 meses, utilizando campo nativo diferido e após pastagem cultivada de inverno [Azevém anual com Trevo Vesiculoso cv. Yuchi (Trifolium vesiculosum)] e novamente campo nativo e pastagem de azevém anual e trevo vesiculoso no segundo período inverno-primavera, concluiram que o acasalamento de novilhas cruzas desmamadas aos 100 dias, aproximadamente, é possível, com animais com peso superior a $110 \mathrm{~kg}$ ao desmame, eficiente programa sanitário e utilização de boas pastagens no período inverno-primavera. Neste mesmo trabalho ao ser avaliada a taxa de repetição de cria, observa-se que a mesma foi de $81,3 \%$ para vacas desterneiradas aos 100 dias pós-parto e $40,3 \%$, para aquelas desterneiradas aos 150 dias pós-parto.

O objetivo deste trabalho foi o de avaliar o desempenho de terneiros submetidos ao desmame aos 90 dias, até um ano de idade, utilizando diferentes forrageiras nos períodos de verão/outono $\mathrm{e}$ inverno/primavera manejados a nível de propriedade rural .

\section{MATERIAIS E MÉTODOS}

O experimento foi desenvolvido nas dependências da Pulquéria Agropecuária, no município de São Sepé, Região fisiográfica da Depressão central do RS, entre janeiro e outubro de 1992. O solo desta localidade é da unidade de mapeamento Cerrito, classificado como laterítico bruno avermelhado distrófico sendo o clima classificado por Köppen como Cfa, com temperatura média anual de $18,7^{\circ} \mathrm{C}$ e precipitação média de 1648 $\mathrm{mm}$ /ano (MACHADO, 1950). Utilizaram-se no experimento 30 animais cruza Nelore X Charolês, com idade entre 90 e 100 dias, por ocasião da primeira pesagem e entrada destes nos potreiros experimentais. As pesagens foram realizadas a cada 28 dias, sendo que antes da primeira e da última pesagem, tanto do período de verão/outono, como do período inverno/primavera, os animais foram submetidos a um jejum de 12 horas. Os animais tiveram acesso 
permanente a sal mineral e água. As desverminações e vacinações foram realizadas conforme o calendário da propriedade e realizou-se banho carrapaticida quando necessário.

Utilizaram-se 4 tratamentos, que eram os sistemas de alimentação: $\left(\mathrm{S}_{1}\right)$ Campo Nativo + Silagem de sorgo (Sorghum bicolor); $\left(\mathrm{S}_{2}\right)$ Campo Nativo + Pastagem cultivada de inverno (Avena strigosa + Lolium multiflorum); $\left(\mathrm{S}_{3}\right)$ Pensacola (Paspalum notatum var. Saurae) + Silagem de sorgo; e $\mathrm{S}_{4}$ ) Pensacola + Pastagem cultivada de inverno. A pastagem cultivada de inverno constou de aveia preta mais azevém, que foi adubada com $150 \mathrm{~kg}$ de NPK/ha da fórmula 12-30-20, na base e mais $40 \mathrm{~kg} / \mathrm{ha}$ de nitrogênio na forma de sulfato de amônia, em cobertura, por ocasião do perfilhamento. A pastagem de pensacola era de segundo ano, sendo que anteriormente a área foi cultivada com soja (Glycine $\max )$.

O lote de animais que recebeu silagem, ficou em campo nativo e foi suplementado com uma mistura de silagem, grão de milho, farinha de carne, sal mineral, uréia e sulfato de amônia, nas seguintes proporções: $83,3 \% ; 15,3 \% ; 1,4 \% ; 0,126 \% ; 0,882 \%$; e $0,098 \%$, respectivamente, para ganhar 0,5 $\mathrm{kg} / \mathrm{animal} / \mathrm{dia}$.

Procurou-se manter um resíduo entre 1200 e 1600kg de matéria seca (MS)/ha (MOOJEN, 1991; MARASCHIN et al., 1993), nas pastagens de verão e entre 1500 e $2000 \mathrm{~kg} \mathrm{MS} /$ ha na pastagem de inverno (WHILOUGBY, 1958; FLOSS, 1988). A silagem foi oferecida na proporção de $3 \%$ de MS, do peso vivo/dia (ISLABÃO, 1988). Os potreiros de campo nativo eram de 20 ha, o de pensacola de 22 ha e o de aveia preta + azevém de 15 ha. O campo nativo era composto basicamente por espécies dos gêneros Paspalum, Axonopus, Andropopogon, Desmodium e da família das compostas. A disponibilidade de MS das pastagens foi estimada com dupla amostragem com estimativas visuais (GARDNER, 1986), usando-se 25 amostras por potreiro, das quais 5 foram cortadas. As amostras cortadas na dupla amostragem, em cada avaliação, eram secas em estufa a $65^{\circ} \mathrm{C}$, até peso constante e após moídas em moinho tipo Willey com peneira de $1 \mathrm{~mm}$, para serem feitas as análises de proteína bruta (PB), pelo método do Micro-Kjeldhal (BREMMER, 1965) e digestibilidade in vitro da matéria orgânica (DIVMO) pelo método de TILLEY \& TERRY (1963), modificado por PIRES et al. (1979). Para a análise da qualidade da silagem, retiraram-se amostras da mesma, em fins de julho e fins de agosto, tanto da silagem pura como da silagem com suplementação.

O sistema de pastejo foi o contínuo com lotação variável, utilizando-se a técnica "Put-and-take" (MOTT \& LUCAS, 1952), para manter a oferta de forragem constante. Os animais reguladores eram bovinos com idade de 1,5 anos para as pastagens de verão e terneiros para as pastagens de inverno. $\mathrm{Na}$ análise estatística, foi feita análise de variância, para o delineamento experimental inteiramente casualisado, comparando-se as médias pelo teste de Tukey, com nível de significância de $5 \%$, quando o teste de $\mathrm{F}$ foi significativo a $5 \%$.

\section{RESULTADOS E DISCUSSÃO}

No período verão/outono, o peso médio dos animais, por ocasião da entrada no experimento em 08/01/92, variava de 98 à $104 \mathrm{~kg} \mathrm{PV}$, para o lote da pensacola e do campo nativo, respectivamente. Ao final do período o peso era de 155 e $149 \mathrm{~kg}$ PV, para campo nativo e pensacola. Foram realizadas 6 pesagens dos animais neste período, sendo que não houve diferença significativa, entre os tratamentos, para o parâmetro peso vivo.

Quanto ao ganho médio diário(GMD) de peso dos animais, também não houve diferença significativa, para este período entre as duas pastagens (Tabela 1). O baixo GMD de peso ocorrido no terceiro sub-período, provavelmente se deve a um problema de verminose, pois por ocasião da pesagem do dia 06/03 os animais foram desvermifugados, com um vermífugo com o princípio ativo Albendazole, e os animais voltaram a ganhar peso. Entre 04 e 24/06, os 30 terneiros foram mantidos em campo nativo, pois a pastagem cultivada de inverno não estava em condições de ser utilizada. O GMD deste período foi de $160 \mathrm{~g}$ /animal.

Tabela 1. Ganho Médio Diário de peso (g/animal/dia) de terneiros desmamados precocemente submetidos a duas pastagens, no período de verão/outono, em São Sepé-RS, 1992.

\begin{tabular}{llrrrrr}
\hline \multicolumn{5}{c}{ Período } \\
\hline Pastagem & $8-24 / 1$ & $24 / 1-8 / 2$ & $8 / 2-6 / 3$ & $6 / 3-4 / 4$ & $4 / 4-5 / 5$ & Média \\
\hline & & & & & & \\
\hline Campo nativo & 619 & 353 & 36 & 346 & 358 & 344 \\
Pensacola & 727 & 437 & -191 & 434 & 293 & 343 \\
\hline
\end{tabular}


No período inverno/primavera realizaram-se quatro pesagens dos animais. Só houve diferença significativa de peso entre os animais nos diferentes sistemas alimentares nas três últimas pesagens, quando os animais que estavam sendo submetidos a pastagem cultivada de inverno tiveram peso superior (Tabela 2), sendo que os dados da última pesagem estão muito próximos do peso médio dos animais avaliados por CRISTALDO \& LOBATO (1990), que foi de $239 \mathrm{~kg}$ aos 365 dias de idade. Porém estes receberam azevém e trevo vesiculoso, no inverno. Isto ocorreu devido ao baixo GMD de peso no primeirio sub-período (Tabela 3), nos tratamentos em que receberam silagem, pois os mesmos passaram por um
Tabela 2. Peso médio de terneiros desmamados precocemente $(\mathrm{kg})$ quando submetidos a dois tipos de alimentação no inverno, em São Sepé, RS, 1992.

\begin{tabular}{lcccc}
\hline & \multicolumn{4}{c}{ Data da Pesagem } \\
\cline { 2 - 5 } & $24 / 06$ & 29,07 & $27 / 08$ & $28 / 09$ \\
\hline Sistema & $161,2 \mathrm{a}$ & $163,5 \mathrm{~b}$ & $175,4 \mathrm{~b}$ & $191,6 \mathrm{~b}$ \\
\hline $\begin{array}{l}\text { Campo nativo + silagem de sorgo } \\
\begin{array}{l}\text { Campo nativo + pastagem de } \\
\text { inverno }\end{array}\end{array}$ & $156,4 \mathrm{a}$ & $188,6 \mathrm{a}$ & $198,7 \mathrm{a}$ & $221,0 \mathrm{a}$ \\
$\begin{array}{l}\text { Pensacola + silagem de sorgo } \\
\text { Pensacola + Pastagem } \\
\text { cultivada de inverno }\end{array}$ & $154,3 \mathrm{a}$ & $154,3 \mathrm{~b}$ & $171,5 \mathrm{~b}$ & $188,8 \mathrm{~b}$ \\
& $150,6 \mathrm{a}$ & $182,1 \mathrm{a}$ & $194,2 \mathrm{a}$ & $226,0 \mathrm{a}$ \\
\hline
\end{tabular}

Nas colunas, médias seguidas de letras diferentes diferem estatisticamente $(P<0,05)$ pelo teste de Tuckey.
Tabela 3. Ganho médio diário de peso (g/an/dia), de terneiros desmamados precocemente e submetidos a dois diferentes tipos de alimentação no inverno, em São Sepé, RS, 1992.

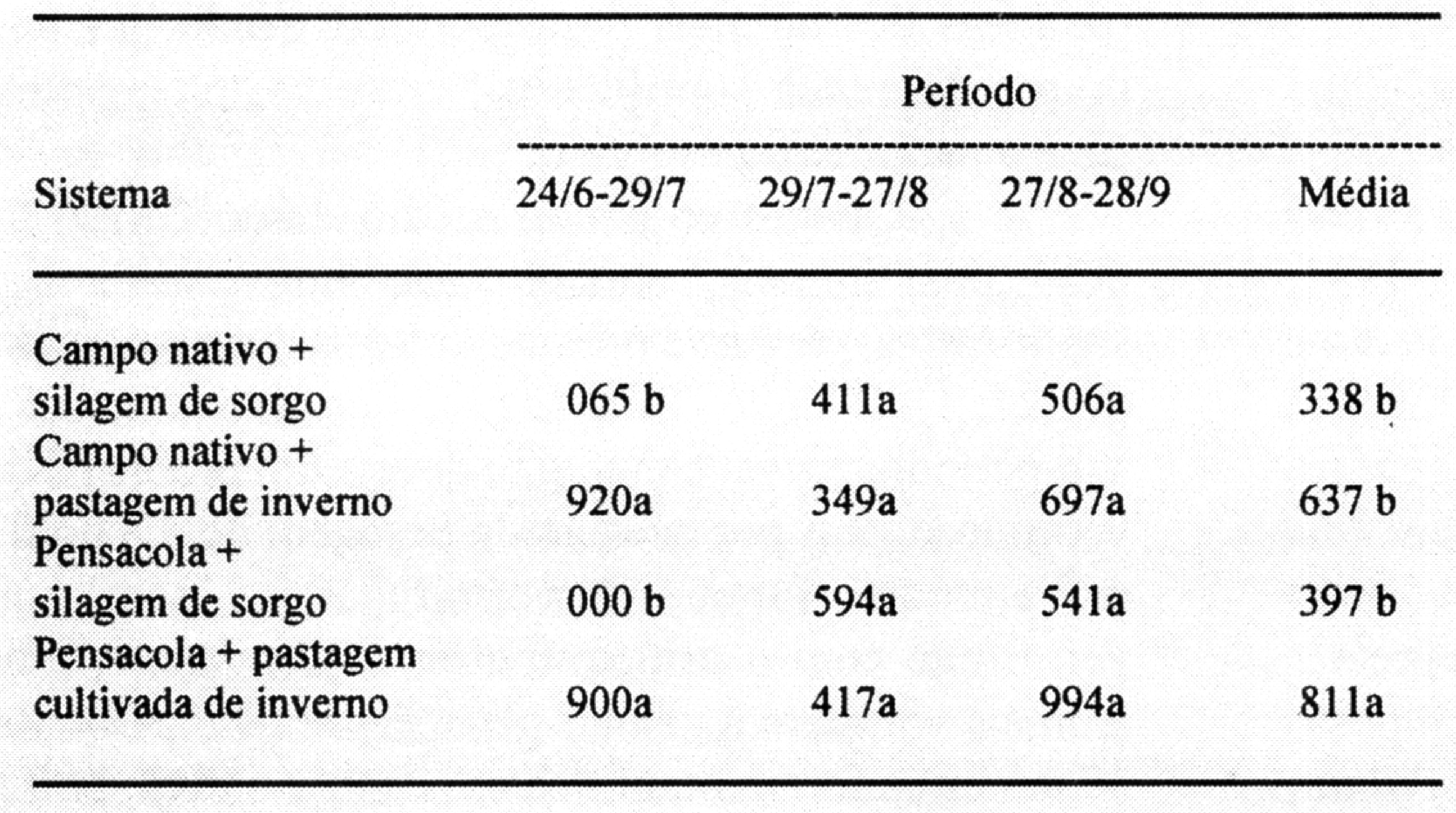

Nas colunas, médias seguidas de letras diferentes diferem estatisticamente $(P<0,05)$ pelo teste de Tuckey.

Tabela 4. Disponibilidade média de matéria seca (MS) e teor de proteina bruta $(\mathrm{PB})$ de uma pastagem de aveia + azevém (kg/MS/ha), quando pastejada por terneiros em São Sepé, RS, 1992.

\begin{tabular}{lcccc}
\hline & \multicolumn{4}{c}{ Data } \\
\cline { 2 - 5 } Pastagem & $24 / 06$ & $29 / 07$ & $27 / 08$ & $28 / 09$ \\
\hline MS (kg/ha) & 871,0 & 511,0 & 1041,0 & 1652,0 \\
PB (\%) & 16,0 b & 13,2 c & $20,8 \mathrm{a}$ & - \\
\hline
\end{tabular}

período de adaptação de aproximadamente 15 dias, quando praticamente não estavam consumindo silagem e perderam peso.

O menor GMD de peso, nos sistemas $\mathrm{S}_{2}$ e $\mathrm{S}_{4}$, no segundo sub-período é devido a baixa disponibilidade de MS, neste período (Tabela 4). Esta redução na disponibilidade deveu-se a um erro no ajuste da lotação por superestimação da área do potreiro. A baixa disponibilidade de MS da pastagem, por ocasião da entrada dos animais no período de inverno ocorreu porque seguiu-se o manejo usual utilizado na propriedade, até a segunda avaliação, quando foi superestimado o tamanho da área. Após, procurou-se elevar a disponibilidade de MS, para a faixa pretendida, o que só foi conseguido por ocasião da última avaliação .

$\mathrm{Na}$ tabela 5, tem-se os dados da disponibilidade de MS nas pastagens no período de verão. Por esta tabela verificamos que até a avaliação de 08/02 foi possível manter a disponibilidade de MS na faixa pretendida, porém à partir da quarta avaliação, o resíduo de MS estava acima da faixa aceitável. Isto ocorreu devido a falta de animais para serem usados como reguladores na pastagem, o que comprometeu o manejo da mesma.

A disponibilidade de MS média na pensacola, apresentou uma tendência a ser superior ao campo nativo em todos os períodos. Em termos de qualidade destas pastagens, não houve diferença significativa entre elas no que diz respeito a teor de PB e DIVMO (Tabela 6), porém o campo nativo apresentou uma tendência de apresentar PB (\%) superior, devido à 
Tabela 5. Disponibilidade média de matéria seca (MS) das pastagens no período de verão (kg MS/ha), em São Sepé, RS, 1992.

\begin{tabular}{lcccccc}
\hline & \multicolumn{5}{c}{ Data } \\
& \multicolumn{7}{c}{ Pastagem } & $08 / 01$ & $24 / 01$ & $08 / 02$ & $06 / 03$ & $04 / 04$ & $05 / 05$ \\
\hline $\begin{array}{l}\text { Campo } \\
\text { nativo }\end{array}$ & 1224 & 1440 & 1327 & 1820 & 2331 & 1937 \\
Pensacola & 1735 & 1596 & 1700 & 2534 & 2745 & 1725 \\
\hline
\end{tabular}

composião florística mais complexa que caracteriza a pastagem natural. Para a pastagem de aveia e azevém, obteve-se valores maiores de PB nas avaliações de 08/07 e 27/08 (Tabela 4). Isto ocorreu devido a pequena contribuição da aveia que estava no fim do seu ciclo e do azevém que ainda não estava com uma contribuição satisfatória e a baixa disponibilidade de folhas na pastagem, pois o resíduo era muito baixo e composto basicamente pelos colmos das plantas.

A análise da qualidade da silagem (Tabela 7), mostra que a suplementação elevou o teor de $\mathrm{PB}$, mas não alterou significativamente o $\mathrm{pH}$, estando o mesmo dentro da faixa aceitável, para uma silagem de boa qualidad e (3,8 a 4,2). A qualidade da silagem esteve constante ao longo do período experimental. $\mathrm{O}$ teor de MS ficou acima do desejável, que é de 28 a $35 \% \quad(\mathrm{PION}-$ NER, 1993), porém não trouxe problemas de anaerobismo em termos de fermentação da silagem.

Tabela 7. Teor de proteína bruta (PB) $(\%)$, teor de matéria seca (MS) (\%) e pH de uma silagem de sorgo com e sem suplementação em duas épocas de coleta, fornecida a terneiros no período de inverno/primavera em São Seoé, RS, 1992.

\begin{tabular}{|c|c|c|c|c|c|c|}
\hline \multirow{3}{*}{ Silagem } & \multicolumn{6}{|c|}{ Data da coleta } \\
\hline & \multicolumn{3}{|c|}{$29 / 07$} & \multicolumn{3}{|c|}{$27 / 08$} \\
\hline & $\mathrm{PB}$ & MS & $\mathrm{pH}$ & $\mathrm{PB}$ & MS & $\mathrm{pH}$ \\
\hline Pura & 6,08 & 37,30 & 3,74 & 4,84 & 36,20 & 3,79 \\
\hline $\begin{array}{l}\text { Suplemen- } \\
\text { tada }\end{array}$ & 9,41 & 42,50 & 4,00 & 6,89 & 31,80 & 4,05 \\
\hline
\end{tabular}

\section{CONCLUSÕES}

Campo nativo e pensacola não diferem entre si, no que diz respeito a ganho médio diário de peso de terneiros, sob pastejo. Os sistemas de alimentação com pastagem cultivada no inverno, são superiores, no que diz respeito a ganho médio diário de peso de terneiros, àqueles com silagem de sorgo, independente destes, no verão, serem submetidos a campo nativo ou pensacola.

\section{REFERÊNCIAS BIBLIOGRÁFICAS}

BREMMER, J.M. Total nitrogen. In: BLACK, C.A. ed. Methods of soils analysis. Madison: American Society of Agronomy. pt.2, 1965. Cap.83, p. 149-178 
CRISTALDO, B.H.J., LOBATO, J.F.P. Desenvolvimento de terneiras desmamadas aos 100 e aos 150 dias. In: REUNIÃO ANUAL DA SOCIEDADE BRASILEIRA DE ZOOTECNIA, 1990, Campinas, SP. Anais... Campinas, Sociedade Brasileira de Zootecnia, 1990. p. 280.

FLOSS, G.L. Manejo forrageiro de aveia (Avena sp.) e azevém (Lolium sp.). In: PEIXOTO, A.M., MOURA, J.C. de, FARIA, V.P. de. Simpósio sobre manejo de pastagens, 9., Piracicaba: FEALQ,1988. p.231-288.

GARDNER, A.L. Técnicas de pesquisa em pastagens e aplicabilidade de resultados em sistemas de produção. Brasília: EMBRAPA-CNPGL, 1986. 197 p.

GRAWUNDER, A.F., MIELITZ NETO, C.G.A. Pecuária de corte no sul do Brasil: que caminhos tomar? Lavoura Arrozeira , Porto Alegre, v.42, n.385, p.24-34, 1989.

GRAWUNDER, A.F., PINHEIRO, J.E., CACHAPUZ, J.M. da S. Desmame aos 90 dias: uma nova alternativa para aumentar a taxa de natalidade do rebanho gaúcho. Porto Alegre: EMATER, 1986. $36 \mathrm{p}$.

IBGE - Fundação Instituto Brasileiro de Geografia e Estatística. Censo Agropécuário: Rio Grande do Sul. Rio de Janeiro: IBGE, 1985. v. 2 t. 3, pt 1.454 p.

ISLABÃO, N. Manual de cálculo de rações. 5.ed. Porto Alegre: SAGRA, 1988. $184 \mathrm{p}$.

LEAL, T.C., FREITAS, J.E., GOMES, D.B. Desmame de terneiros de corte aos 90 dias de idade visando o aumento da eficiência reprodutiva das vacas. Anuário Técnico do Instituto de Pesquisa Zootécnica "Francisco Osório", Porto Alegre, v. 5, p. $173-177,1978$.

MACHADO, F.P. Contribuição ao estudo do clima do RS. , Rio de Janeiro: IBGE-Conselho Nacional de Geografia, 1950. 91 p.
MARASCHIN, G.E., MOOJEN, E.L., ESCOSTEGUY, C.M.D. et al. Natural pasture, forage on offer and animal response. PortoAlegre: Universidade Federal do Rio Grande do Sul, 1993. 10 p. (Apostila)

MOOJEN, E.L. Dinâmica e potencial produtivo de uma pastagem nativa do Rio Grande do Sul, submetida a pressóes de pastejo, épocas de diferimento e níveis de adubaçăo. Porto Alegre, RS, 172 p. Tese (Doutorado em Zootecnia), Faculdade de Agronomia, Universidade Federal do Rio Grande do Sul, 1991.

MOTT, G.O., LUCAS H.L. The design, conduction and interpretation of grazing trails on cultivated and improved pastures. In: INTERNATIONAL GRASSLAND CONGRESS, 1952. Pensylvania State College. Proceedings... Pensylvania, State College, 1952. p.1380-1385.

PIONNER. Silagem. Santa Cruz do Sul: PIONNER Sementes, 69 p. (Boletim informativo, p. 63-69).

PIRES, M.B.G., FREITAS, E.A.G., TRINDADE, D.S. et al. Estabelecimento de um sistema de digestibilidade in vitro no laboratório da equipe de pesquisa em nutrição animal da Secretaria da Agricultura do RS. Anuário Técnico do Instituto de pesquisa Zootécnica "Francisco Osório". Porto Alegre, , v.6, p.345-385, 1979.

TILLEY, J.M., TERRY, R.A. Two way technic for the in vitro digestion of forage crops. Journal of the British Grassland Society, London, v. 18, p. 104-111, 1963.

WHILLOUGBY, W.M. The relationship of pasture availability and animal production. In: BIENIAL CONFERENCE, 1958, Canberra. Proceedings... Canberra, Australian Society of Animal Production, 1958. v. 2. p. 42-45. 